\title{
FACTORS INFLUENCING CHOLINE ABSORPTION IN THE INTESTINAL TRACT ${ }^{1}$
}

\author{
By J. DE LA HUERGA AND HANS POPPER \\ (From the Hektoen Institute for Medical Research and the Departments of Pathology of the \\ Cook County Hospital and Northwestern University Medical School, Chicago, Illinois)
}

(Submitted for publication January 7, 1952; accepted April 14, 1952)

Previous investigations (1) have demonstrated that in normal persons approximately 60 per cent of choline salts fed in a single dose is transformed by intestinal bacteria to trimethylamine (TMA), which is excreted in the urine mainly as the oxide. In chronic liver diseases, considerably less of the ingested choline appears in the urine as total trimethylamines (TTMA). This difference was considered as evidence of an altered action of the intestinal bacteria in these diseases (1). The concept of the intestinal formation of urinary trimethylamines, based in part upon the reduction of TTMA excretion following administration of antimicrobial agents, was confirmed by the observation (2) that choline as such appears in the urine after intravenous administration of choline, but the basal excretion of urinary TTMA is not altered significantly. The concept of altered choline utilization by intestinal bacteria in liver diseases, as reflected by reduced transformation of choline to TMA, required further elaboration. This was partly carried out in animal experiments (3), but in addition it was necessary to perform a series of clinical studies to clarify the results of human and animal investigations reported previously. Studies of the physiologic processes included the following: (a) whether choline bound in the form of phospholipids is transformed to TMA to the same degree as are choline salts, (b) investigation into the site and completeness of intestinal transformation of choline, and (c) determination of the effects of aureomycin upon the transformation of large amounts of choline. Studies of the alteration of intestinal transformation of choline in liver disease were concerned with (a) the specificity of reduced TTMA excretion in hepatic disease, (b) the effect of large amounts of choline upon the TTMA excretion in cirrhosis, and (c) the experimental alteration of

1 Supported by a grant from the Doctor Jerome D. Solomon Memorial Research Foundation. intestinal flora by prolonged feeding of choline on the premise that bacteria, such as Proteus vulgaris known to transform choline $(4,5)$, would increase at the expense of such bacteria as Escherichia coli and coliform paracolons which do not utilize this substance.

\section{MATERIAL AND METHODS}

Patients were selected with hepatic diseases, particularly cirrhosis, and non-hepatic diseases such as pneumonia, leukemia, cancer, and rheumatoid arthritis. Normal persons (staff of the Hektoen Institute) served as controls. Urine and stool samples were collected for TTMA or choline determination after oral administration of a test dose of choline as bicarbonate. ${ }^{2}$ In all urine samples, the TTMA were determined by treating the urine with Devarda's alloy followed by aeration (1). The total 24-hour excretions were expressed as TTMA N. Not taken into account was the basal urinary TTMA excretion, which varies from 5.7 to $15.0 \mathrm{mg}$. $\mathrm{N}$ in 24 hours (1), but is relatively constant with the same diet. Four normal persons and two patients with cirrhosis were given 20 grams of a purified lecithin orally which was found to contain $230 \mathrm{mg}$. choline nitrogen, determined according to the technic of Handler (6). Urine specimens were collected 24 hours prior to and for two consecutive 24hour periods immediately following administration of lecithin. In three cirrhotics, the contents of different levels of the intestinal tract were obtained by a MillerAbbott tube. The ability of these contents to transform choline to TMA was tested, as described previously, by incubation of a small amount in a tryptose medium containing 1 per cent choline chloride (1). Total bacteria counts were also done on these contents. In an additional experiment $10 \mathrm{ml}$. of the same medium were inoculated with stools of two normal persons and three patients with cirrhosis, and choline and trimethylamine concentrations were determined and compared after incubation. In two instances, 4 grams of choline base as bicarbonate were given orally, together with 0.5 gram of carmine as a stool marker, and total feces were collected. Fractional stools were kept in a frozen state until the total feces were obtained. The feces were homogenized, weighed, and 100 grams extracted with $100 \mathrm{ml}$. of alcohol. After cen-

2 Thanks are due to Commercial Solvents Corporation for a generous supply of the choline salts used in these experiments. 
trifugation the solids were re-extracted four times in the same way. The total alcohol extracts were evaporated and the residue taken up in $25 \mathrm{ml}$. $\mathrm{N}$ hydrochloric acid. This was treated with Norit $A$ and allowed to stand for one hour. After filtration an aliquot was taken for determination of choline, as described previously for urine (1).

In two patients with non-hepatic disease, the urinary TTMA were determined after a test dose of 10 grams of choline base. The patients were then given 0.5 gram of aureomycin orally six times daily for five consecutive days. The test dose of choline was repeated during the last day of aureomycin administration and the urinary TTMA determined. In another series three normal persons received 4 grams of choline base twice one week apart, the second time with the addition of $500 \mathrm{mg}$. aureomycin. Urinary TTMA excretion was determined on the first and second day following choline administration.

Nine normal persons, 39 patients with hepatobiliary disease, especially cirrhosis, and 11 patients suffering from different severe non-hepatic disease received 2 grams of choline base (230 mg. choline $\mathrm{N}$ ). The urines subsequently collected for a 24-hour period were examined for TTMA.

In two patients with cirrhosis, the TTMA excretion following the intake of 2 grams of choline base was determined five days prior to and after the administration of $\mathbf{5}$ grams of choline base twice a day for two consecutive days. An interval of five days was chosen to allow the return to basal TTMA excretion before administration of the second test dose.

Nine patients with cirrhosis were treated for two weeks with three daily oral doses of 2 grams of choline base as choline citrate, and the TTMA excretion was redetermined five days after discontinuance of treatment.
Total bacteria counts, as well as the percentage of $E$. coli and coliform paracolons, were determined before and following choline treatment. The stools were weighed and thoroughly homogenized with saline under sterile precautions. Serial dilutions from $10^{-3}$ to $10^{-15}$ were prepared. Duplicate plates with tryptose agar and eosinmethylene blue medium (Difco) were inoculated with each dilution, using the pour-plate technic for the first, and the surface-swabbing method for the second type of plate. Twenty-four and 48 hours later the number of bacterial colonies was counted and representative members of each colony type identified by morphologic, tinctorial and biochemical properties, according to the classification of Bergey's manual (7). In one patient in this group the bacteriologic studies were repeated and in three other patients the determination of urinary TTMA after a test dose of 2 grams of choline was repeated two to three weeks after the discontinuance of prolonged choline administration. In all nine patients in this group, the cephalin flocculation, thymol turbidity, serum albumin, cholesterol ester, total cholesterol ratio, and lipid phosphorus (as determined by standard technics) were compared prior to and following choline administration.

\section{RESULTS}

\section{Study of physiologic processes}

a. Lecithin administration. Urinary excretion of TTMA following the intake of an amount of lecithin containing 2 grams of choline base was considerably lower than following the intake of the same amount of choline in the form of bicar-
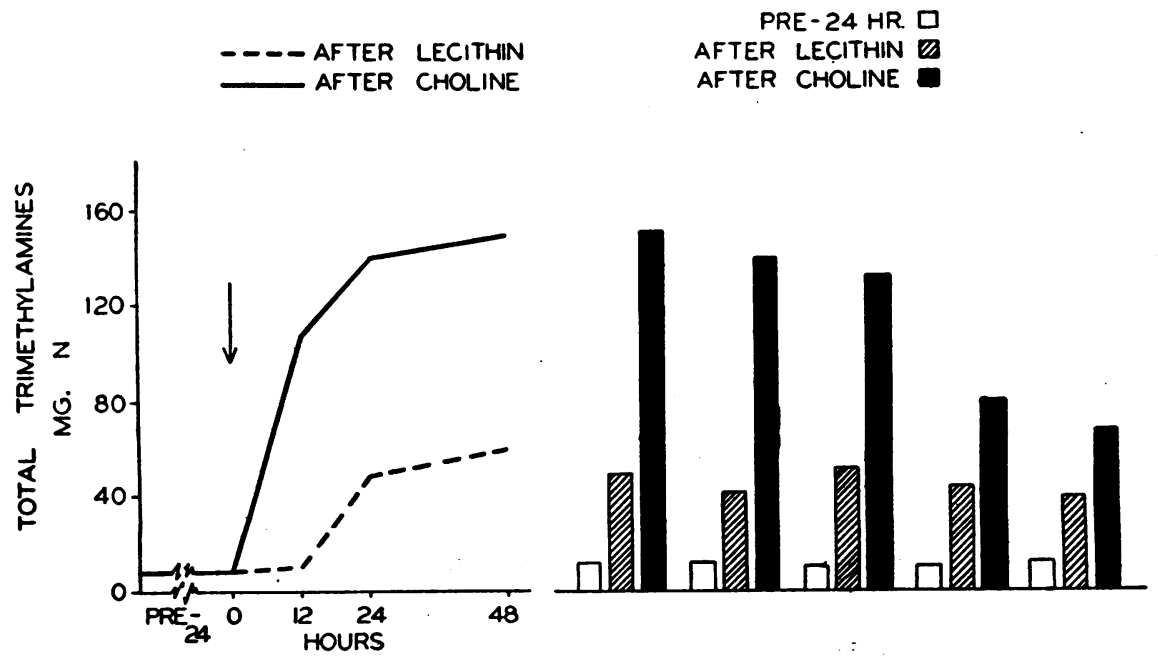

Fig. 1. Excretion of Total Trimethylamines Before and in the 24-hour Periods Following Oral Intake of Choline and Lecithin Containing the Same Amount of Choline Nitrogen (230 mg. N)

The curve and the first three groups of bars represent four normals, the last two bars two patients with hepatic cirrhosis. 
TABLE I

Tolal bacterial counts and per cent of choline in medium transformed to trimethylamine by the contents of different levels of the gastro-intestinal tract in three patients with hepatic cirrhosis

\begin{tabular}{|c|c|c|c|c|c|c|}
\hline \multirow{2}{*}{$\begin{array}{l}\text { Site or } \\
\text { distance } \\
\text { (in feet) } \\
\text { from } \\
\text { pylorus }\end{array}$} & \multicolumn{2}{|c|}{ Case 1} & \multicolumn{2}{|c|}{ Case 2} & \multicolumn{2}{|c|}{ Case 3} \\
\hline & $\begin{array}{c}\text { Bacterial } \\
\text { count } \\
\text { (per ml. })\end{array}$ & $\begin{array}{l}\text { Per cent } \\
\text { choline } \\
\text { trans- } \\
\text { formed }\end{array}$ & $\begin{array}{c}\text { Bacterial } \\
\text { count } \\
\text { (per ml.) }\end{array}$ & $\begin{array}{l}\text { Per cent } \\
\text { choline } \\
\text { trans- } \\
\text { formed }\end{array}$ & $\begin{array}{l}\text { Bacterial } \\
\text { count } \\
\text { (per ml.) }\end{array}$ & $\begin{array}{l}\text { Per cent } \\
\text { choline } \\
\text { trans- } \\
\text { formed }\end{array}$ \\
\hline $\begin{array}{c}\text { Stomach } \\
\text { Duodenum } \\
1 \\
2 \\
3 \\
4 \\
5 \\
5 \\
6 \\
7\end{array}$ & $\begin{array}{r}881 \\
82 \\
4,280 \\
1,037 \\
1,719 \\
437 \\
4,398 \\
5,372 \\
5,732\end{array}$ & $\begin{array}{r}38 \\
0 \\
25 \\
47 \\
43 \\
45 \\
49 \\
54 \\
59\end{array}$ & $\begin{array}{r}11,520 \\
5,760 \\
1,760 \\
10,386 \\
6,912 \\
1.024 \\
1,792 \\
382\end{array}$ & $\begin{array}{l}50 \\
0 \\
42 \\
37 \\
45 \\
42 \\
51 \\
44 \\
47\end{array}$ & $\begin{array}{l}\frac{1,400}{120} \\
\frac{500}{700} \\
\frac{70}{-}\end{array}$ & $\begin{array}{l}\frac{40}{35} \\
\frac{46}{58} \\
\frac{30}{30}\end{array}$ \\
\hline
\end{tabular}

bonate (Figure 1). In addition, the bulk of TTMA appeared in the urine in 12 hours or less after ingestion of choline as such, whereas after ingestion of lecithin, the bulk of TTMA appeared in the urine between 12 and 24 hours. In cirrhosis, ingestion of lecithin is followed by the same TTMA excretion as in normals. This is in contrast to the decreased TTMA excretion in cirrhosis after choline intake. If the basal TTMA excretion is deducted, the 24-hour TTMA excretion in normal persons after lecithin ingestion was only 26.1 per cent of the TTMA excretion after ingestion of equivalent amounts of choline; in the two cirrhotics it was 50.1 per cent of the excretion after choline.

b. Transformation of choline by gastro-intestinal content. In the three instances studied, choline was transformed to TMA by the contents

TABLE II

Choline and trimethylamine nitrogen content of a tryptose medium (containing $1 \mathrm{mg}$. choline nitrogen per ml.) inoculated with stools and incubated for 24 hours at $37^{\circ} \mathrm{C}$

The control represents an incubated but not inoculated medium.

\begin{tabular}{l|c|c|c}
\hline \hline & \multicolumn{3}{|c}{ Medium } \\
\cline { 2 - 4 } Diagnosis & Choline N & TMA N & Choline \\
& & & TMA N \\
\hline & mg./ml. & mg./ml. & mg./ml. \\
& 0.47 & 0.55 & 1.02 \\
Normal & 0.50 & 0.50 & 1.00 \\
Normal & 0.45 & 0.57 & 1.02 \\
Cirrhosis & 0.37 & 0.61 & 0.98 \\
Cirrhosis & 0.53 & 0.49 & 1.02 \\
Cirrhosis & 0.00 & 0.98 & 0.98 \\
Control & & & \\
\hline
\end{tabular}

of the stomach and small intestine, except in the duodenum. This ability to transform choline paralleled the presence of bacteria (Table I). Choline-containing culture media inoculated with the stool of two normals and three cirrhotics revealed, after incubation, a sum of choline and TMA $\mathrm{N}$ equivalent to the choline $\mathrm{N}$ originally present (Table II). The TMA concentration of

TABLE III

Influence of aureomycin treatment upon urinary excretion of total trimethylamines after oral administration of 10 grams choline base in the form of bicarbonate

$\begin{array}{cc}\text { TTMA excretion (mg. } N \text { per } 24 \text { hours) } \\ \begin{array}{c}\text { Before aureomycin } \\ \text { treatment }\end{array} & \begin{array}{c}\text { During aureomycin } \\ \text { treatment }\end{array} \\ 802.0 & 6.3 \\ 670.0 & 116.6\end{array}$

Tuberculosis of hip Fracture
116.6

a TMA-containing medium did not change after inoculation with feces, indicating that intestinal bacteria transform choline only to TMA and not to a substance unaccounted for by the method used. In neither one of the normal persons who had taken orally 4 grams of choline with 100 grams of starch (which has been shown [1] to suppress intestinal TMA formation) nor in the one cirrhotic who excreted low amounts of TTMA after choline could significant amounts of choline (not more than 4 per cent of the dose given) be demonstrated in the feces.

TABLE IV

Urinary excretion of total trimethylamines of three normals after intake of 4 grams choline base (equivalent to $460 \mathrm{mg}$. choline $N$ ) with and without simultaneous oral administration 500 mg. aureomycin

\begin{tabular}{c|c|c|c|c}
\hline & \multicolumn{2}{|c|}{$\begin{array}{c}\text { Without aureomycin } \\
\text { (mg. TTMA } N)\end{array}$} & \multicolumn{2}{|c}{$\begin{array}{c}\text { With aureomycin } \\
(\text { mg. TTMA N })\end{array}$} \\
\cline { 2 - 5 } $\begin{array}{c}\text { Hours after } \\
\text { choline intake. }\end{array}$ & $0-24$ & $24-48$ & $0-24$ & $24-48$ \\
\hline No. 1 & 230.0 & 34.5 & 47.0 & 10.8 \\
No. 2 & 240.0 & 36.0 & 71.0 & 25.8 \\
No. 3 & 222.0 & 31.0 & 87.0 & - \\
\hline
\end{tabular}

c. Administration of aureomycin. Even after administration of 10 grams of choline base, the TTMA excretion was decidedly reduced if aureomycin were given (Table III). In the two cases studied, the amount excreted was lower than the usual excretion of TTMA after administration of 2 grams of choline in the absence of aureomycin, and in one it was below normal basal excretion of 


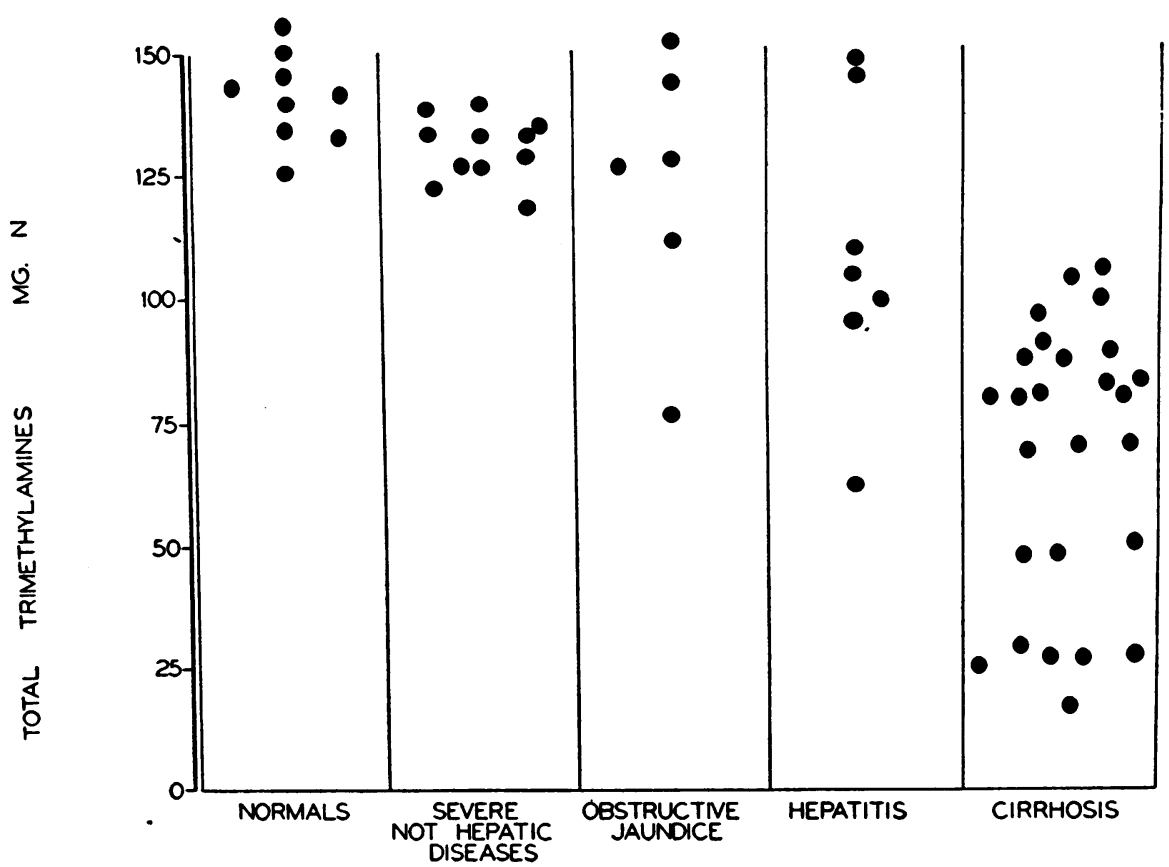

Fig. 2. Distribution of the Amount of Total Trimethylamines Excreted in the Urines in the 24-hour Period Following the Intake of 2 Grams of Choline Base (230 mg. N) in Normals and in Patients with Various Diseases

about $10 \mathrm{mg}$. TTMA nitrogen in 24 hours. The administration of a single small dose of aureomycin together with choline suppressed the TTMA excretion markedly, even on the second day after administration (Table IV).

2. Alteration of intestinal transformation of choline in diseases

a. Specificity of reduced TTMA excretion for liver disease. The histogram (Figure 2) shows clearly that in cirrhosis, TTMA excretion after a test dose of choline was significantly and consistently reduced in comparison with normals, whereas in acute hepatitis and particularly in obstructive jaundice the reduction was less constant. In patients with severe disease without apparent hepatic involvement, the excretion was almost within the normal range.

b. Effect of large doses of choline. The TTMA excretion after a test dose of choline in two cir-

TABLE V

Influence of prolonged treatment with choline upon urinary total trimethylamines excretion in patients with cirrhosis of liver . after oral administration of choline bicarbonate corresponding to $230 \mathrm{mg} . N$, upon the total stool bacterial count, and upon the percentage of colon bacilli and coliform paracolons from the total stool bacteria

\begin{tabular}{|c|c|c|c|c|c|c|c|c|}
\hline \multicolumn{3}{|c|}{$\begin{array}{l}\text { TTMA excretion } \\
\text { (mg. } N \text { per } 24 \text { hours) }\end{array}$} & \multicolumn{3}{|c|}{$\begin{array}{l}\text { Total bacterial count } \\
\text { (per gm. stood) }\end{array}$} & \multicolumn{3}{|c|}{$\begin{array}{l}\text { Colon bacilli and coliform paracolons } \\
\text { (percentage of total count) }\end{array}$} \\
\hline $\begin{array}{c}\text { Before } \\
\text { choline } \\
\text { treatment }\end{array}$ & $\begin{array}{l}5 \text { days } \\
\text { after }\end{array}$ & $\begin{array}{l}20 \text { days } \\
\text { after }\end{array}$ & $\begin{array}{l}\text { Before choline } \\
\text { treatment }\end{array}$ & 5 days after & 20 days after & $\begin{array}{c}\text { Before } \\
\text { choline } \\
\text { treatment }\end{array}$ & $\begin{array}{l}5 \text { days } \\
\text { after }\end{array}$ & $\begin{array}{l}20 \text { days } \\
\text { after }\end{array}$ \\
\hline $\begin{array}{r}87.9 \\
113.0 \\
82.1 \\
49.5 \\
48.5 \\
96.5 \\
73.0 \\
91.2 \\
88.0\end{array}$ & $\begin{array}{l}156.8 \\
148.0 \\
148.5 \\
141.9 \\
126.6 \\
141.7 \\
146.0 \\
157.7 \\
129.5\end{array}$ & $\begin{array}{r}117.0 \\
82.0 \\
85.0\end{array}$ & $\begin{array}{l}5.1 \times 10^{8} \\
8.6 \times 10^{8} \\
3.5 \times 10^{11} \\
2.4 \times 10^{11} \\
1.1 \times 10^{10} \\
5.2 \times 10^{9} \\
2.1 \times 10^{6} \\
1.8 \times 10^{8}\end{array}$ & $\begin{array}{l}7.9 \times 10^{7} \\
8.0 \times 10^{7} \\
1.3 \times 10^{11} \\
7.9 \times 10^{12} \\
2.7 \times 10^{11} \\
4.3 \times 10^{8} \\
2.4 \times 10^{6} \\
2.5 \times 10^{8}\end{array}$ & $2.9 \times 10^{6}$ & $\begin{array}{l}14.7 \\
17.8 \\
65.2 \\
54.1 \\
7.3 \\
27.8 \\
10.5 \\
\\
30.4\end{array}$ & $\begin{array}{r}5.7 \\
16.3 \\
43.2 \\
0.7 \\
0.1 \\
0.4 \\
6.2 \\
\\
11.3\end{array}$ & 62.5 \\
\hline
\end{tabular}


rhotics, who had previously received 20 grams of choline in two days, did not vary significantly from their excretion following a test dose (69.5 and $27.2 \mathrm{mg}$. TTMA $\mathrm{N}$ without previous choline treatment in 24 hours compared with 62.0 and $33.0 \mathrm{mg}$. afterwards).

c. Influence of prolonged choline treatment. Following prolonged daily administration of choline to nine patients with cirrhosis (with and without jaundice), the TTMA excretion after a test dose of choline, which was initially reduced, rose to normal. These differences were significant in all instances (Table V). No significant differences occurred in the results of the hepatic tests during this period.

In three cases in whom a third test dose of choline was given from two to three weeks after discontinuance of the daily choline treatment, the urinary TTMA fell again to almost the level before treatment. The total bacterial count did not change significantly in eight cases in which bacterial studies of the stool were performed. During treatment, the percentage of the coliform bacteria dropped markedly in four instances, moderately in three, and only slightly in one. In the one instance in which the investigation was repeated several weeks after discontinuance of daily choline treatment, the percentage of coliform bacteria had risen significantly.

\section{DISCUSSION}

The experiments presented were designed to clarify the phenomena described previously (1), that intestinal bacteria destroy the bulk of intestinal choline and that this process is reduced in liver disease. It has been shown that intestinal bacteria do not degrade choline to nitrogenous substances other than trimethylamine. Ingested trimethylamine chloride is almost quantitatively excreted in the urine (1), indicating that it undergoes no degradation in the body once it is formed from choline. No matter how low the urinary TTMA excretion is, the feces do not contain significant amounts of choline in humans or rats (3). This indicates that low TTMA excretion is not due to loss of choline in the stool. These observations lead to the conclusion that reduced urinary TTMA excretion in liver disease is associated with increased choline absorption. That this is a specific occurrence in chronic liver disease is supported by the observations that in severe systemic disease without significant liver involvement, TTMA excretion is normal, and that in animal experiments significant reduction of urinary TTMA excretion occurs only in chronic but not in acute hepatic injury (3). The reduced urinary TTMA excretion in chronic liver disease can be explained either by increased absorption of choline (preventing a larger portion than normal from being destroyed by intestinal bacteria) or by a primary alteration of the bacteria so that they utilize less choline and more remains to be $a b-$ sorbed. The important role of bacteria is suggested by the significant reduction of the TTMA excretion by simultaneous administration even of single doses of aureomycin with choline. Topographically, bacterial degradation of choline starts very high in the intestine, near a level where choline absorption can be assumed to begin from our knowledge of lipid absorption (8). At first thought, the hypothesis of primary alteration of bacterial activity is also supported by observations on the effect of prolonged choline treatment. This treatment did not alter hepatic function, but elevated the abnormally low TTMA excretion to the normal level, and discontinuance of the therapy resulted in a return to subnormal levels. If bacterial determinations in the stools can be relied upon to reflect changes of bacteria in the intestine, elevation of TTMA excretion after prolonged choline treatment in these studies was associated with a significant decrease of the percentage of noncholine-utilizing bacteria. However, there is no evidence that the intestinal flora contain an abnormally high percentage of non-choline-utilizing bacteria in liver disease. It is possible, therefore, that these experiments do not represent a correction of an abnormal process, but an unusual overload of the intestinal content favoring more rapid multiplication of the bacteria which transform choline. A primary alteration of intestinal choline absorption would be supported by the finding that when choline is given as lecithin, much less is excreted as TTMA than when the same amount is given as free choline. It is possible that choline absorption is associated with lecithin formation in the intestinal wall. Choline deficiency in the patients, possibly associated with an increased 
avidity for choline, could be excluded as the cause of altered TTMA excretion in liver diseases, since temporary overloading of the body with choline by administration of large amounts for a short time did not influence the reduced TTMA excretion.

The evidence presented here, therefore, strongly suggests an increased absorption of choline in chronic liver disease, but whether this is the result of altered bacterial action or altered permeability of the intestinal wall remains to be established.

\section{SUMMARY}

Attempts have been made to elaborate upon the observation reported previously that the bulk of choline administered orally is transformed in the intestinal tract to trimethylamine, which is excreted in the urine mainly as the oxide, and that this excretion is diminished in liver disease (1). The transformation by intestinal bacteria starts in the upper part of the intestinal tract. Choline not so transformed is assumed to be absorbed, since intestinal bacteria are unable to transform choline to nitrogenous substances other than trimethylamine and no significant amounts of choline could be found in the stool, even when trimethylamine formation was depressed.

Trimethylamine formation can be changed by alteration of bacterial flora. Choline, in amounts as large as 10 grams, can be protected from bacterial action by the administration of aureomycin; the administration of a single dose of 0.5 gram of aureomycin significantly reduced the transformation of $\mathbf{4}$ grams of choline base. Oral administraof choline for two weeks usually results in depression of the percentage of non-choline-utilizing bacteria in the stool and leads regularly to an increase of the originally reduced trimethylamine excretion in liver disease. Discontinuance of treatment re- sults in a decrease of trimethylamine excretion to initial levels.

The reduction of trimethylamine excretion appears specific for liver disease; it was not found in other severe diseases studied.

The TTMA excretion does not increase as much after the administration of lecithin as after the administration of an equivalent amount of choline, suggesting that a greater amount of choline is absorbed if it is given in bound form. It is tentatively assumed that choline absorption is increased in liver disease.

\section{REFERENCES}

1. de la Huerga, J., and Popper, H., Urinary excretion of choline metabolites following choline administration in normals and patients with hepatobiliary diseases. J. Clin. Invest., 1951, 30, 463.

2. de la Huerga, J., Popper, H., and Steigmann, F., Urinary excretion of choline and trimethylamines after intravenous administration of choline in liver diseases. J. Lab. \& Clin. Med., 1951, 38, 904.

3. Popper, H., de la Huerga, J., and Koch-Weser, D., Fate of choline in rats with and without experimental hepatic injury. J. Lab. \& Clin. Med., in press.

4. Cohen, G. N., Nisman, B., and Raynaud, M., Sur la dégradation bactérienne de la choline et de la colamine. Compt. rend. Acad. sc., 1947, 225, 647.

5. Dyer, F. E., and Wood, A. J., Action of enterobacteriaceal on choline and related compounds. J. Fisheries Research Board, Canada, 1947, 7, 17.

6. Handler, $P$., The determination of choline in biological material. Biol. Symposia, 1947, 12, 361.

7. Breed, R. S., Murray, E. G. D., and Hitchens, A. P., Bergey's Manual of Determinative Bacteriology. The Williams \& Wilkins Company, Baltimore, 1948, 6th edition.

8. Volk, B. W., and Popper, H., The influence of dispersion upon absorption of vitamin $A$ and fat as studied by fluorescent microscopy. Gastroenterology, 1950, 14, 549 . 